\title{
Do Community Pharmacies in Saudi Arabia Provide Medication-Related Information to Nonbuyers? A Mysterious Shopper Survey
}

\author{
Hani M. J. Khojah ${ }^{*}$, Ahmed M. E. Abdalla² \\ ${ }^{1}$ Department of Clinical and Hospital Pharmacy, College of Pharmacy, Taibah University, Madinah, KSA \\ ${ }^{2}$ Department of Pharmaceutics and Pharmaceutical Technology, College of Pharmacy, Taibah University, Madinah, KSA \\ Email: *hkhojah@taibahu.edu.sa
}

How to cite this paper: Khojah, H.M.J. and Abdalla, A.M.E. (2019) Do Community Pharmacies in Saudi Arabia Provide Medication-Related Information to Nonbuyers: A Mysterious Shopper Survey. Pharmacology \& Pharmacy, 10, 169-176.

https://doi.org/10.4236/pp.2019.104015

Received: March 12, 2019

Accepted: April 15, 2019

Published: April 18, 2019

Copyright $\odot 2019$ by author(s) and Scientific Research Publishing Inc. This work is licensed under the Creative Commons Attribution International License (CC BY 4.0).

http://creativecommons.org/licenses/by/4.0/

\begin{abstract}
Background: Patient counseling service is an integral component of pharmacy practice in the community pharmacy. Counseling services should be provided to patients regardless of whether the patient has the intention to buy a medication or not. Objective: The aim of this study is to investigate the effect of the conflict between ethics and business objectives in Saudi Arabian private community pharmacies on patient counseling. Methods: Eighty pharmacies were randomly selected in Madinah, Saudi Arabia, and visited by mysterious shoppers following a preplanned scenario. Clients requested information on the correct use of a dry powder inhaler for bronchial asthma. A survey form was filled in by the clients immediately after the visit. Results: seventy-five pharmacies were included in the study. Seventy-seven percent of the pharmacists gave a varying content of information although the client showed no intention to buy the medication. Only $5 \%$ of pharmacists gave the full instructions regarding the correct handling of the device and using it for taking the correct dose. Around $68 \%$ of the pharmacists focused only on how to take the dose. Four percent of the pharmacists provided insufficient information. Around $23 \%$ of the pharmacists refused to give any information and referred the shopper to other sources for obtaining the required information. Conclusions: Although most of the pharmacists provided free counseling, the amount and level of information provided were generally insufficient. This illustrates the need for introducing clear policies and guidelines for providing free professional counseling services to patients in the community pharmacy setting in Saudi Arabia.
\end{abstract}

\section{Keywords}

Patient Counseling, Patient Education, Drug Information, Community 
Pharmacy, Saudi Arabia

\section{Introduction}

The fact that community pharmacies are highly accessible to patients has extended pharmacists' role on patient care far beyond prescription dispensing [1]. Patient counseling and education are a fundamental part of pharmacy practice in community pharmacy [2] [3]. Several studies have shown that patient counseling can help pharmacists to detect and solve drug-related problems [4] [5], assist patients to implement positive self-management attitude [5] [6] [7], improve patient satisfaction with services provided in the pharmacy [8] [9], enhance patient quality of care [6] [10] and reduce the negative economic implications of drug misuse [11]. This practice should be provided to patients regardless of whether the patient has the intention to buy a medication or not. It is worth emphasizing that patient education and counseling are not necessarily provided at the time of prescription dispensing but rather it could be provided as a separate service [3].

Although there is no regulation in Saudi Arabia that obliges community pharmacists to provide information to patients with no intention to buy medications, it is considered an ethical issue that pharmacists offer appropriate advice about the use of medications regardless of the financial incentives. It has been reported that community pharmacy economical structure represents a barrier against patient counseling and that community pharmacy owners stress upon financial issues rather than services [12].

Some studies have assessed community pharmacists' performance and patients' satisfaction with pharmacists' role in various cities in the Kingdom of Saudi Arabia. A study has shown that the level of professional performance in community pharmacies in the city of Riyadh is improving and that patients have demonstrated higher levels of perception and satisfaction of the community pharmacists' role [13]. In this study, $44.3 \%$ of the patients participated in the study thought that the community pharmacist role is not only concerned with the prescription dispensing practice. On the other hand, the author concluded that there is still a need for improvement in the quality of services provided in the community pharmacy and that pharmacists need to improve their knowledge and skills to provide better health care services. Another study has demonstrated that almost a quarter of the respondents of a survey, conducted in Riyadh, believed that community pharmacies have a balanced performance between financial and health care services, where $56.1 \%$ of the respondents thought that pharmacists were more concerned with business rather than health care services [14]. However, in a study of the ability of the community pharmacists, in the province of Qassim, to demonstrate the proper use of medications to patients, the authors have found out that $93.7 \%$ of the pharmacists failed to give reasonable information [15]. Moreover, a study conducted in the city of Da- 
wadmi has demonstrated that consumers perceive that pharmacists are not committed to provide sufficient counseling services in community pharmacy setting. The authors also reported that $48 \%$ of the consumers participated in the latter study felt uncomfortable to ask questions to pharmacist [16].

The simulated client method proved to be a reliable method for the assessment of counseling services in pharmacy setting [17] [18] [19]. Several studies used this method to test pharmacist performance while providing dispensing and counseling services to patients [20] [21] [22] [23] [24]. In this method, well trained individuals visit the pharmacy as "mysterious shoppers" to perform a preplanned scenario that assesses the quality of the services provided by the pharmacists.

The aim of this study is to investigate the effect of the conflict between ethics and business objectives in community pharmacy, in Saudi Arabia, on patient counseling using the mysterious shopper method.

\section{Methods}

\subsection{Ethical Issues}

Because this study involves mysterious shoppers, the Research Ethics Committee at Taibah University in Madinah, Saudi Arabia, approved the waiver of an informed consent to avoid expected changes in the pharmacists' behaviors. The study was conducted in Madinah, Saudi Arabia, during November 2018.

\subsection{Selection of Community Pharmacies}

A total of 353 private community pharmacies were found in the database of Madinah's Health Affairs. Each pharmacy was given a unique serial number and Microsoft Excel 2016 (Microsoft Company, the United States) was used to randomly select 80 pharmacies. A pharmacy would be excluded if it was not found on the specified location, was out of business or was closed on a second visit.

\subsection{The Mysterious Shopper Scenario}

Four pharmacy students have voluntarily participated as the mysterious shoppers so that each of them has visited 20 pharmacies. To ensure consistency of performance, the students were trained through role-playing to perform a preplanned scenario inside the pharmacy. The scenario involved asking the pharmacist about the correct use of a certain brand of dry powder inhaler, containing a corticosteroid, for bronchial asthma using an empty package brought by the shopper claiming that it has been prescribed to his/her old mother by a physician who did not educate them about the proper use of it. Based on the information found on the medication pamphlet, the pharmacist is expected to respond to this inquiry by educating the client on the proper use and provide him/her with information regarding how to prepare the new device before use, how to take an inhalation, when to start using a new inhaler, and the need for rinsing the mouth with water after each use of the inhaler. The mysterious shoppers 
have been requested to record their observations in a certain form prepared specifically for this purpose.

\subsection{The Survey Form}

A special form was completed by each shopper after leaving the pharmacy. Pharmacy name, the name of the mysterious shopper, and time and date of the visit were recorded in the header of the form that was then folded and stapled by the shopper to keep the researchers blind to such information during form analysis. Expected pharmacist responses were listed as checkboxes in the body of the form. If the pharmacist gives all the necessary information regarding the correct use, handling and keeping of the inhaler, already mentioned in the pamphlet of the medication, the response will be considered full response. However, if the pharmacist only mentions how to take the dose the response will be considered fair, and if the pharmacist gives only technical information without focusing on the dosage the response will be considered insufficient. In addition, if the pharmacist does not give any information, the reason will be documented. Finally, the leader of the shoppers team collected all forms, shuffled them and returned them to the primary investigator.

\subsection{Confidentiality}

Personal information was not obtained from any pharmacy. Pharmacy names were kept confidential.

\subsection{Data Analysis}

Ratios and frequencies were employed as descriptive analyses of the results of this survey.

\section{Results}

Three pharmacies out of the selected 80 where not found on the location mentioned in the database and two other pharmacies were found closed at the second visit. Thus, the total number of included pharmacies was 75. As illustrated in Table 1, around 75\% of the pharmacies belonged to certain chains and the vast majority of the pharmacists were non-Saudis. Around 79\% of the pharmacists were Egyptians while the remaining nationalities included Syrians, Pakistanis, Sudanese, Jordanians, Indians and Yemenis. All of the community pharmacists in this study were men except one Saudi woman.

Regarding the information given (Table 2), it was found that around $77 \%$ of the pharmacists responded by giving certain information although they were aware that the client was not having the intention to buy the medication. However, as low as $5 \%$ of them gave the full instructions on how to prepare the device for use, how to take the dose, and how to handle and keep the medication after use. Around $68 \%$ of the pharmacists focused only on how the dose must be taken and $4 \%$ of them offered insufficient information. 
Table 1. Summary of pharmacy information.

\begin{tabular}{cc}
\hline Information & $\mathbf{N}(\%)$ \\
\hline Type of pharmacy & $56(74.7)$ \\
Chain & $19(25.3)$ \\
Independent & \\
Pharmacist Nationality & $3(4.0)$ \\
Saudi & $72(96.0)$ \\
Non-Saudi & \\
Pharmacist sex & $74(98.7)$ \\
Male & $1(1.3)$ \\
Female &
\end{tabular}

Table 2. Summary of pharmacist responses.

\begin{tabular}{cc}
\hline Response & N (\%) \\
\hline Giving fullinformation* & $4(5.3)$ \\
Giving fair information & $51(68.0)$ \\
Giving insufficient information & $3(4.0)$ \\
Referring to physician & $10(13.3)$ \\
Referring to the pamphlet & $2(2.7)$ \\
Referring to online search & $5(6.7)$ \\
\hline
\end{tabular}

*As per the medication pamphlet. Full response means giving all necessary information regarding the correct use, handling and keeping of the inhaler. Fair response means mentioning only how to take the dose. Insufficient response means giving only technical information without focusing on the dosage.

Unfortunately, around $23 \%$ of the pharmacists refused to give any information and requested the client either to refer to the physician who prescribed the medication, to refer to the pamphlet, or to search for the instructions online.

\section{Discussion}

The results have shown that the majority of private community pharmacies, regardless of whether they were members of chains or independent, were willing to offer drug-related information to nonbuyers. Although this reasonably high rate may be considered acceptable, however, the content of the information given was not generally accepted. This observation was found to follow the same pattern of poor patient counseling documented in other previous studies conducted in main cities of Saudi Arabia [14] [15] [16] [22] [25]. Internationally, counseling rates stated in literature were found to vary from $8 \%$ to $100 \%$, depending on the research method used [17].

It was noted in this study that in around $94 \%$ of the visited pharmacies there was only one pharmacist available for customer services. This makes it difficult for the pharmacy to offer appropriate services especially when the pharmacy is crowded. Therefore, increasing the number of on duty community pharmacists in Saudi Arabia is highly recommended. 
Another important insufficiency observed in the visited pharmacies is that the ratio of female-to-male pharmacists in private community pharmacies in Saudi Arabia is extremely low ( $1.3 \%$ in this study), which may make consultations about sensitive issues embarrassing to the pharmacist and female customers taking into consideration the Islamic cultural norms followed by the country.

As shown in the results, it was found that in around a quarter of the pharmacies the pharmacists did not offer the nonbuyers any information on the correct use of the medication. Although this behavior may reflect an existing conflict between business objectives and community pharmacy practice ethics, it was not observed in all pharmacies that belong to the same chain. Other reasons behind such behavior could be attributed to poor knowledge and undergraduate training of the pharmacists and the availability of only one pharmacist on duty, making the provision of additional services difficult.

Finally, for private community pharmacies in Saudi Arabia to optimize their role in community service, fulfilling the requirements of the vision of this steadily developing country, they must include patient education and offer drug information as a separate service in a special designated area inside the pharmacy. The authorities in Saudi Arabia are strongly advised to adopt strict regulations and follow-up monitoring to ensure the provision of optimal services by private community pharmacies.

\section{Limitations of the Study}

The current study focused on only one medication that requires a special technique for administration. However, it is expected that a similar pattern of pharmacist behavior would be observed with other medications because our results are parallel to other studies conducted in Saudi Arabia. Second, the random selection of pharmacies was performed by the second investigator, who was not blinded to pharmacy identities but, however, data analysis was performed by the first investigator, who was blinded to such information. Finally, although the study was conducted in one major city of Saudi Arabia, the results can be extrapolated to the whole kingdom because most of the previous studies conducted in other cities have shown a similar pattern of practice.

\section{Conclusion}

The current study highlighted the performance of private community pharmacists regarding providing counseling services to customers who have no intention to buy their medication using the mysterious shopper methodology. Although most of the pharmacists provided some counseling services, the amount of information provided was insufficient. This indicates that improvement of the counseling services is required, and clear policies and guidelines should be developed to standardize the level of services provided in community pharmacies throughout Saudi Arabia. It is also advisable to modify the layout of the community pharmacies to include a patient counseling area to deliver the informa- 
tion regarding medication use in a more confidential and professional environment.

\section{Acknowledgements}

The authors would like to thank Ms. Razan Mofti, Mr. Bassam Khoshhal, Ms. Reham Alharbi and Mr. Abdulrahman Almalki for playing the role of mysterious shoppers in this study.

\section{Conflicts of Interest}

The authors declare no conflicts of interest regarding the publication of this paper.

\section{References}

[1] Melton, B.L. and Lai, Z. (2017) Review of Community Pharmacy Services: What Is Being Performed, and Where Are the Opportunities for Improvement? Integrated Pharmacy Research and Practice, 6, 79-89.

[2] Ghaibi, S., Ipema, H. and Gabay, M. (2015) ASHP Guidelines on the Pharmacist's Role in Providing Drug Information. American Journal of Health-System Pharmacy, 72, 573-577. https://doi.org/10.2146/sp150002

[3] American Society of Health-System Pharmacists (1997) ASHP Guidelines on Pharmacist-Conducted Patient Education and Counseling. American Journal of Health-System Pharmacy, 54, 431-434.

[4] Rantucci, M.J. (2007) Pharmacists Talking with Patients: A Guide to Patient Counseling. Lippincott Williams \& Wilkins, Philadelphia.

[5] Chandra, A., Malcolm, N. and Fetters, M. (2003) Practicing Health Promotion through Pharmacy Counseling Activities. Health Promotion Practice, 4, 64-71. https://doi.org/10.1177/1524839902238293

[6] Wu, J.Y., Leung, W.Y., Chang, S., Lee, B., Zee, B., Tong, P.C. and Chan, J.C. (2006) Effectiveness of Telephone Counselling by a Pharmacist in Reducing Mortality in Patients Receiving Polypharmacy: Randomised Controlled Trial. British Medical Journal, 333, 522. https://doi.org/10.1136/bmj.38905.447118.2F

[7] Smith, L., Bosnic-Anticevich, S.Z., Mitchell, B., Saini, B., Krass, I. and Armour, C. (2007) Treating Asthma with a Self-Management Model of Illness Behaviour in an Australian Community Pharmacy Setting. Social Science and Medicine, 64, 1501-1511. https://doi.org/10.1016/j.socscimed.2006.11.006

[8] Liu, M.V., Jennings, J.P., Samuelson, W.M., Sullivan, C.A. and Veltri, J.C. (1999) Asthma Patients' Satisfaction with the Frequency and Content of Pharmacist Counseling. Journal of the American Pharmaceutical Association (1996), 39, 493-498. https://doi.org/10.1016/S1086-5802(16)30467-3

[9] Tinelli, M., Bond, C., Blenkinsopp, A., Jaffray, M., Watson, M. and Hannaford, P. (2007) Patient Evaluation of a Community Pharmacy Medications Management Service. Annals of Pharmacotherapy, 41, 1962-1970. https://doi.org/10.1345/aph.1K242

[10] Ebid, A. and Abdel-Wahab, E. (2006) Bronchial Asthma and COPD: Impact of Pharmaceutical Care on Outcomes and Quality of Life in Egyptian Patients (2006). Bulletin of Pharmaceutical Sciences-Assiut University, 29, 167.

[11] Svarstad, B.L., Bultman, D.C. and Mount, J.K. (2004) Patient Counseling Provided in Community Pharmacies: Effects of State Regulation, Pharmacist Age, and Busy- 
ness. Journal of the American Pharmaceutical Association, 44, 22-29. https://doi.org/10.1331/154434504322713192

[12] Raisch, D.W. (1993) Patient Counseling in Community Pharmacy and Its Relationship with Prescription Payment Methods and Practice Settings. Annals of Pharmacotherapy, 27, 1173-1179. https://doi.org/10.1177/106002809302701002

[13] Al-Arifi, M.N. (2012) Patients' Perception, Views and Satisfaction with Pharmacists' Role as Health Care Provider in Community Pharmacy Setting at Riyadh, Saudi Arabia. Saudi Pharmaceutical Journal, 20, 323-330. https://doi.org/10.1016/j.jsps.2012.05.007

[14] Bawazir, S.A. (2004) Consumer Attitudes Towards Community Pharmacy Services in Saudi Arabia. International Journal of Pharmacy Practice, 12, 83-89. https://doi.org/10.1211/0022357023718

[15] Adnan, M., Karim, S., Khan, S. and Al-Wabel, N.A. (2015) Comparative Evaluation of Metered-Dose Inhaler Technique Demonstration among Community Pharmacists in Al Qassim and Al-Ahsa Region, Saudi-Arabia. Saudi Pharmaceutical Journal, 23, 138-142. https://doi.org/10.1016/j.jsps.2014.06.007

[16] Alotaibi, H.S. and Abdelkarim, M.A. (2015) Consumers' Perceptions on the Contribution of Community Pharmacists in the Dispensing Process at Dawadmi. Saudi Pharmaceutical Journal, 23, 230-234. https://doi.org/10.1016/j.jsps.2014.11.002

[17] Puspitasari, H.P., Aslani, P. and Krass, I. (2009) A Review of Counseling Practices on Prescription Medicines in Community Pharmacies, Research in Social and Administrative Pharmacy, 5, 197-210.

[18] Norris, P. (2004) Reasons Why Mystery Shopping Is a Useful and Justifiable Research Method. Pharmaceutical Journal, 272, 746-747.

[19] Watson, M.C., Skelton, J.R., Bond, C.M., Croft, P., Wiskin, C.M., Grimshaw, J.M. and Mollison, J. (2004) Simulated Patients in the Community Pharmacy Setting-Using Simulated Patients to Measure Practice in the Community Pharmacy Setting. Pharmacy World and Science, 26, 32-37. https://doi.org/10.1023/B:PHAR.0000013467.61875.ce

[20] Horvat, N., Koder, M. and Kos, M. (2012) Using the Simulated Patient Methodology to Assess Paracetamol-Related Counselling for Headache. PLOS ONE, 7, e52510.

[21] Hussain, A., Ibrahim, M.I. and Malik, M. (2013) Assessment of Disease Management of Insomnia at Community Pharmacies through Simulated Visits in Pakistan. Pharmacy Practice, 11, 179-184. https://doi.org/10.4321/S1886-36552013000400001

[22] Kashour, T.S., Joury, A., Alotaibi, A.M., Althagafi, M., Almufleh, A.S., Hersi, A. and Thalib, L. (2016) Quality of Assessment and Counselling Offered by Community Pharmacists and Medication Sale without Prescription to Patients Presenting with Acute Cardiac Symptoms: A Simulated Client Study. European Journal of Clinical Pharmacology, 72, 321-328.

[23] Weiss, M.C., Booth, A., Jones, B., Ramjeet, S. and Wong, E. (2010) Use of Simulated Patients to Assess the Clinical and Communication Skills of Community Pharmacists. Pharmacy World and Science, 32, 353-361. https://doi.org/10.1007/s11096-010-9375-Z

[24] Schneider, C.R., Everett, A.W., Geelhoed, E., Kendall, P.A. and Clifford, R.M. (2009) Measuring the Assessment and Counseling Provided with the Supply of Nonprescription Asthma Reliever Medication: A Simulated Patient Study. Annals of Pharmacotherapy, 43, 1512-1518. https://doi.org/10.1345/aph.1M086

[25] Alaqeel, S. and Abanmy, N.O. (2015) Counselling Practices in Community Pharmacies in Riyadh, Saudi Arabia: A Cross-Sectional Study. BMC Health Services Research, 11, 179-184. https://doi.org/10.1186/s12913-015-1220-6 